\title{
Interaction between cigarettes and propranolol in treatment of angina pectoris
}

\author{
KIM FOX, ANNE JONATHAN, HUW WILLIAMS, ANDREW SELWYN
}

\section{Summary and conclusions}

To determine whether cigarette smoking interferes with the medical management of angina pectoris, 10 patients with angina pectoris who smoked at least 10 cigarettes a day were studied before, during, and after a standardised maximal exercise test. This was done at the end of four randomly allocated one-week treatment periods during which the patients took glyceryl trinitrate while not smoking, took glyceryl trinitrate while smoking, took glyceryl trinitrate and propranolol $(360 \mathrm{mg} /$ day $)$ while not smoking, and took glyceryl trinitrate and propranolol while smoking. Carboxyhaemoglobin was measured to ensure compliance. Smoking was associated with a significantly higher heart rate, blood pressure, number of positions with ST-segment depression, and total STsegment depression after exercise than non-smoking $(p<0.01)$ whether or not the patients were taking propranolol.

These results suggest that smoking aggravates the simple haemodynamic variables used to assess myocardial oxygen requirements and the exercise-induced precordial electrocardiographic signs of myocardial ischaemia. These effects were still evident after treatment with propranolol and represent a hindrance to the effective medical treatment of angina pectoris.

\section{Introduction}

The epidemiological relation between cigarette smoking and ischaemic heart disease is well known to patients and physicians. Fewer people, however, are aware of the direct effects of smoking on the heart, though a relation between smoking and angina has long been known. ${ }^{1}$ Smoking causes an increase in the systemic release of catecholamines. ${ }^{2}$ In addition it directly affects adrenergic nerve endings. ${ }^{1}$ This leads to increases in resting heart rate and blood pressure, both of which have been observed in patients with ischaemic heart disease and normal controls. ${ }^{2}{ }^{3}$ Although cigarette smoking by patients with angina causes a significant decrease in exercise tolerance before the onset of angina pectoris, ${ }^{4}$ the effects of smoking on exercise heart rate and blood pressure and the resultant myocardial ischaemia have not been clearly defined.

The interaction between cigarette smoking and propranolol in patients with angina has not been investigated, despite its great practical importance in the medical management of such patients. We carried out a study in which we used isopotential mapping of the electrocardiogram ${ }^{5}$ to describe the heart rate, blood pressure, and precordial distributions of pathological ST-segment changes before, during, and after exercise in 10 patients with angina pectoris. The patients were studied while taking and not taking propranolol and while smoking and not smoking.

Cardiovascular Unit, Hammersmith Hospital, London W12 0HS

KIM FOX, MB, MRCP, senior registrar

ANNE JONATHAN, technician

HUW WILLIAMS, MB, senior house officer

ANDREW SELWYN, MB, MRCP, lecturer

\section{Patients and methods}

We studied 10 men aged 46-62 (mean 51) years; all had a typical history of angina pectoris on effort, and the results of an exercise test were positive. All patients smoked at least 10 cigarettes a day and agreed to stop smoking as directed for periods of one week.

All patients underwent a "run-in" period of one week during which they smoked but did not receive propranolol. Each patient was then randomly allocated to four one-week treatment periods: (a) smoking and taking propranolol (120 mg three times daily); (b) smoking and not taking propranolol; $(c)$ no smoking and taking propranolol (120 mg three times daily); and (d) no smoking and not taking propranolol. At the end of each treatment period an exercise test was performed and venous blood drawn for assay of carboxyhaemoglobin concentration.

\section{EXERCISE TEST}

All patients underwent precordial mapping of the electrocardiogram before and for 10 minutes after exercise on a bicycle ergometer. ${ }^{45}$ Sixteen adhesive electrodes were equally spaced to cover the left hemithorax. A four-way switch and four-channel Elema-Schonander electrocardiograph were used to record rapidly the 16 complexes of each map. The technical details and reproducibility of this method have been described. ${ }^{5} 6$

A maximal exercise test was performed at the end of the run-in period, and the work load achieved by each patient was noted. The same work load was then performed at the end of each treatment period. Each exercise test was performed two hours postprandially, one hour after the last cigarette in the run-in period and treatment periods $(a)$ and $(b)$, and two hours after the last dose of propranolol in treatment periods $(a)$ and $(c)$.

The heart rate calculated from the electrocardiogram, systolic blood pressure measured by palpation at the wrist, and ST-segment depression were recorded before exercise, at each minute during exercise, at peak exercise, and $0,1,3,5,8$, and 10 minutes after exercise. STsegment depression of $1 \mathrm{~mm}$ or more and sustained for $0.08 \mathrm{~s}$ or longer was regarded as important. ${ }^{7}$ The calibration was $10 \mathrm{~mm}=1 \mathrm{mV}$. In each map the number of positions showing ST-segment depression (area) and the total ST-segment depression for the 16 leads (severity) were calculated.

\section{CARBON MONOXIDE}

To ensure compliance carboxyhaemoglobin was measured before each exercise test by a spectrophotometric method. We included in this study only patients in whom during the no-smoking periods the carboxyhaemoglobin concentration fell to less than $2 \%$.

\section{Results}

The carboxyhaemoglobin concentration was $8 \cdot 2 \pm 2.8 \%$ (mean \pm 1 SD) during the smoking periods and $1 \cdot 1 \pm 0.3 \%$ during the no-smoking periods. In all patients the carboxyhaemoglobin concentration was greater than $4 \%$ during the smoking periods and less than $2 \%$ during the no-smoking periods.

Figures 1 and 2 show the effects of smoking with and without propranolol on heart rate and blood pressure. Smoking was associated with a significantly higher heart rate and blood pressure than nosmoking before, during, and after exercise $(p<0.001)$ whether or not the patients were taking propranolol $(p<0.01)$. Similarly, when the area and severity of ST-segment changes at peak exercise and after exercise were compared smoking was associated with more pronounced ST-segment changes than no-smoking ( $p<0.01$-figs 3 and 4) whether or not the patients were taking propranolol. 


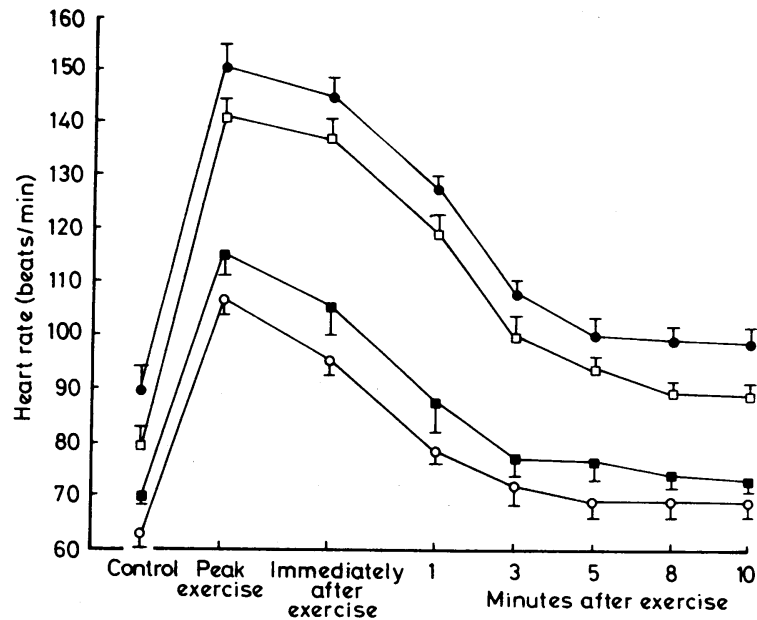

FIG 1-Effects of smoking and propranolol on heart rate before, during, and after exercise in 10 patients with ischaemic heart disease. Results are expressed as means \pm SEM.

$\theta=$ Smoking, no propranolol. $\square=$ No smoking, no propranolol. - Smoking + propranolol. $O=$ No smoking + propranolol.

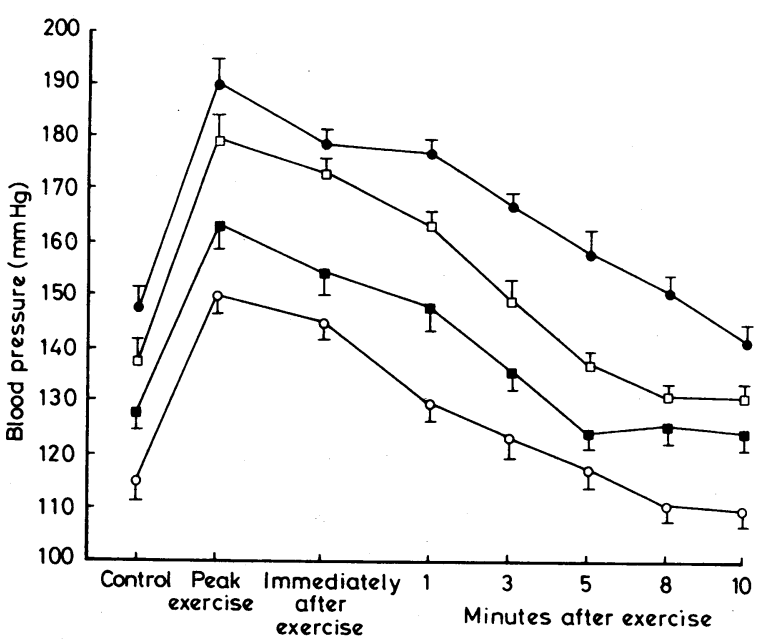

FIG 2-Effects of smoking and propranolol on systolic blood pressure before, during, and after exercise. Results are expressed as means \pm SEM. For key see figure 1 .

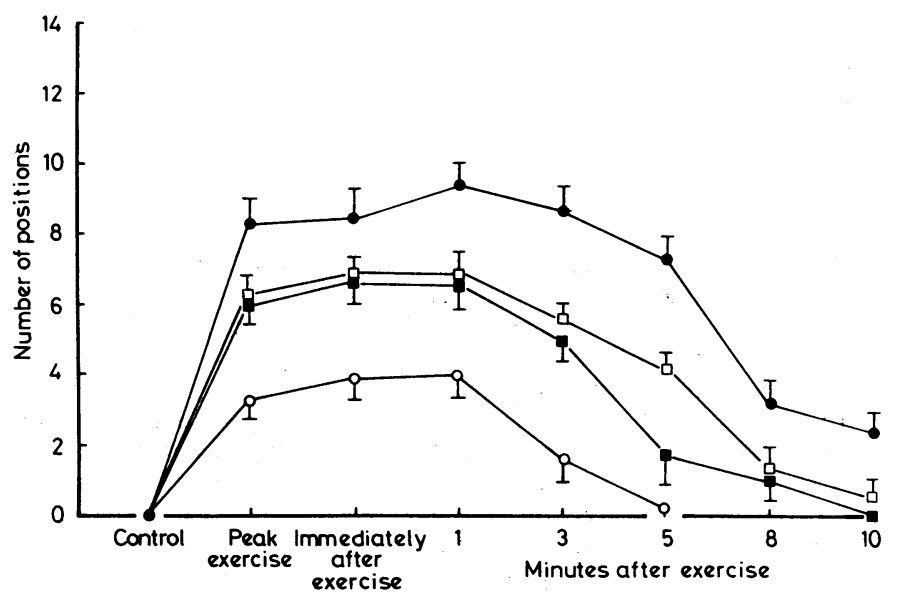

FIG 3-Effects of smoking and propranolol on area of ST-segment changes before, during, and after exercise. Results are expressed as means \pm SEM. For key see figure 1 .

\section{Discussion}

This study shows that smoking has a direct haemodynamic effect on the heart, causing an increase in heart rate and blood pressure. This effect was found before, during, and after exercise and is probably due to the direct effects of the absorbed nicotine. ${ }^{4}$ The effects were still seen when patients were treated with conventional doses of propranolol.

By using each patient as his own control smoking was found to increase both the area and severity of the electrocardiographic manifestations of myocardial ischaemia. Although treatment with propranolol limited the extent of these changes, the deleterious effects of smoking were still evident with the drug.

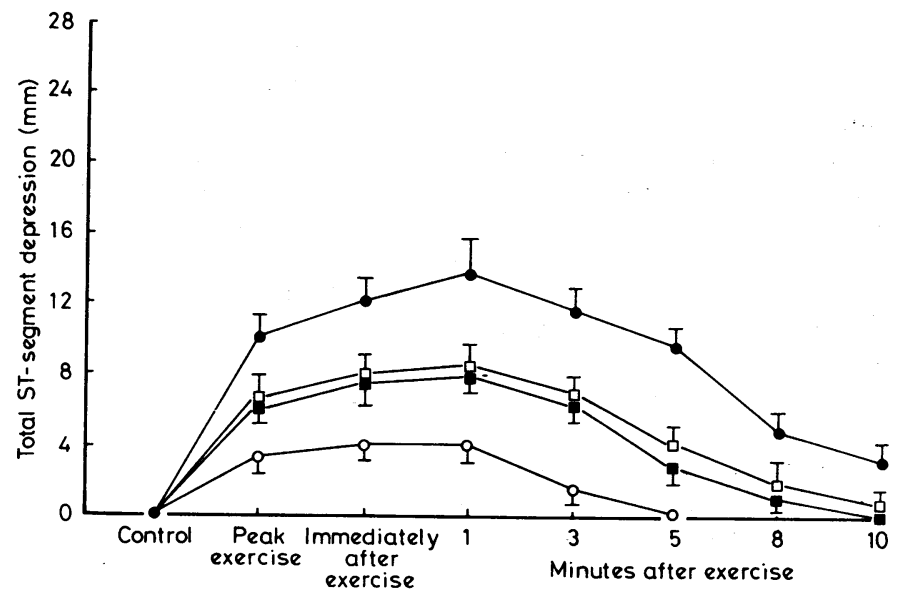

FIG 4-Effects of smoking and propranolol on severity of ST-segment changes before, during, and after exercise. Results are expressed as means \pm SEM. For key see figure 1 .

Indeed, interestingly, no significant differences were found in the area and severity of ST-segment changes when patients were smoking but taking oral propranolol and when they were not smoking and not taking this drug. Thus the usual beneficial effects expected from treatment with propranolol were almost negated by the cigarettes.

Other workers have found that smoking increases the heart rate and blood pressure at rest and after exercise. The effects on the ST segment have not been clearly defined in these studies, which have included large numbers of patients and compared smokers and non-smokers. Only by studying each patient as his own control and by measuring the electrocardiographic changes is it possible to draw conclusions about the effects of smoking on the ST segment.

The changes in heart rate and blood pressure that occurred with smoking are probably due to direct nicotine stimulation of catecholamines and on the postsympathetic ganglia. ${ }^{2}$ The increase in the product of the heart rate and blood pressure will increase myocardial oxygen demand at any given work load, hence potentially increasing the severity of myocardial ischaemia. In addition, the oxygen-carrying capacity of the blood is diminished in smokers, reducing the amount of oxygen available for aerobic metabolism. ${ }^{8}$ Both factors are probably of some importance in causing the deterioration of electrocardiographic signs of myocardial ischaemia found during the treatment periods when patients smoked.

These simple haemodynamic effects of smoking may be expected to limit the usual beneficial effects of beta-receptor antagonists on heart rate, blood pressure, and the ST segment. Furthermore, propranolol is eliminated from the body almost wholly by metabolic transformation in the liver with the resultant products excreted in the urine. ${ }^{\circ}$ Smoking stimulates hepatic drug-metabolising enzymes and directly reduces plasma concentrations of propranolol. 1011 
Carboxyhaemoglobin concentrations were used to assess compliance. Only patients in whom the concentrations fell to under $2 \%$ during the no-smoking period were included in the study. Concentrations of up to $2 \%$ during no-smoking periods are acceptable: non-smokers living and working in the City of London have a mean concentration of $1.3 \% .{ }^{12}$ During the smoking periods our patients had carboxyhaemoglobin concentrations in excess of $4 \%$.

This study has shown that smoking in addition to its known epidemiological associations has direct and adverse effects on the heart. These were still evident after treatment with propranolol and represent a hindrance to the effective medical treatment of angina pectoris.

Requests for reprints should be addressed to Dr K M Fox.

\section{References}

1 Oram S, Sowton E. Tobacco angina. $Q \mathcal{J}$ Med 1963;32:115-43.

${ }^{2}$ McHenry PL, Farris JV, Jordan JW, Morris SN. Comparative study of cardiovascular function and ventricular premature complexes in smokers and non-smokers during maximal treadmill exercise. Am f Cardiol 1977; 39:493-8.
${ }^{3}$ Aronow WS, Cassidy J, Vangrow JS, et al. The effect of cigarette smoking and breathing carbon monoxide on cardiovascular hemodynamics in anginal patients: Circulation 1974;50:340-7.

4 Aronow WS, Kaplan MA, Jacob D. Tobacco: a precipitating factor in angina. Ann Intern Med 1968;69:529-36.

5 Fox K, Selwyn A, Shillingford J. Precordial exercise mapping: improved diagnosis of coronary artery disease. $\mathrm{Br}$ Med $\mathcal{f}$ 1978;ii:1956-8.

${ }^{6}$ Fox KM, Selwyn AP, Shillingford JP. A method for precordial surface mapping of the exercise electrocardiogram. Br Heart f 1978;40:1339-43.

7 Mason RE, Likar I, Biern RO, Ross RS. Multiple lead exercise electrocardiography. Experience in 107 normal subjects and 67 patients with angina pectoris and comparison with coronary cinearteriography in 84 patients. Circulation 1967;36:517-25.

${ }^{8}$ Aronow WS, Rokaw SN. Carboxyhaemoglobin caused by smoking nonnicotine cigarettes: effects in angina pectoris. Circulation $1971 ; 44$ : $782-8$.

9 Routledge PA, Shand DG. Clinical pharmacokinetics of propranolol. Clin Pharmacokinet 1979;4:73-90.

10 Wood AJJ, Vestal RE, Branch RA, Wilkinson GR, Shand DG. Age related effects of smoking on elimination of propranolol, antipyrine and indocyanine green. Clinical Research 1978;26:297A.

11 Walle T, Conradi EC, Walle UK, Fagan TC, Gaffney TE. The predictable relationship between plasma levels and dose and chronic propranolol therapy. Clin Pharmacol Ther 1978;24:668-77.

12 Castleden CM, Cole PV. Carboxyhaemoglobin levels of smokers and nonsmokers working in the City of London. Br $\mathcal{F}$ Ind Med 1975;32:115-8.

(Accepted 22 May 1980)
Four years ago I reported ${ }^{1}$ the preliminary results of a study designed to discover whether women could be persuaded to examine their breasts regularly and, if so, whether regular self-examination increased the rate of diagnosis of early breast cancer. Two women's organisations in Finland co-operated and 56000 of their members aged 20 to 80 years enrolled in the study. Person-to-person education and instruction were arranged and these were supplemented by mass communication through television, radio, and the press. Surgeons and radiologists in different parts of Finland agreed to see women who had detected signs by self-examination. The results of the combination of mass health education and personal instruction were encouraging and after two years about $70 \%$ of the women were persisting with regular self-examination.

Since then there has been a continuing national educational programme, the "Mama Programme," and I report a study of its results.

\section{Subjects, methods, and results}

The population studied consisted of 56177 women aged 20 years or over in the whole of Finland. The Mama Programme consists of person-toperson instruction, follow-up inquiry into persistence of self-examination and the results of it, television education, and the provision of medical specialists whom women who detect signs may consult.

Before the start of the programme all of a group of 4000 women interviewed knew of the need for monthly self-examination of the breasts but only $2 \%$ of them practised it regularly. Since the start of the programme almost $67 \%$ of 2900 women in one area have examined themselves regularly each month.

In the first year of the programme 750 of the 56177 women consulted a medical specialist. One out of every eight of them had a new breast cancer and 90 self-detected new cases were registered. In the second year about 300 consulted a specialist and 35 self-detected new cancers were registered. The 90 new self-detected cases in the first year was almost double the figure expected from the incidence recorded in Finland for the previous year. Cases of local carcinoma numbered $63(70 \%)$ and the mean age of the patients was about 10 years younger than expected. Cases of duct carcinoma were about double the expected number. Cases of carcinoma with axillary spread numbered 27 , compared with the 39.55 that could have been expected from the Finnish Cancer Register. The mortality expected for a group similar to that in the study was 28.75 , but in fact only 15 of the new cases detected in the programme died.

A sharp rise in the incidence of breast cancer in Finland during 1973-80 was not predicted. In 1972, the year before the start of the Mama Pro- gramme, there were 1126 new cases of breast cancer. In 1973 there were 1301 cases and in 1976 1406. Since 1975 the Mama Programme has been introduced to about 100000 more women each year, and it is recommended by health authorities. The number of registered cases of breast cancer has risen sharply since the programme was introduced.

\section{Comment}

The results show that the programme has greatly reduced the mortality in new breast cancer cases. The incidence of breast cancer in Finland is low. In countries where it it high a long-term educational programme of this kind could be of great value. Breast cancer screening cannot be arranged for all women-at all events, not often enough. A programme of self-examination is not hindered by numbers and is effective.

${ }^{1} \mathrm{G}$ Gästrin. New technique for increasing the effeciency of self-examination in early diagnosis of breast cancer. Br MedF 1976;ii :745-6.

(Accepted 2 April 1980)

Radiological Society of Finland, P Box 21, 00571 Helsinki 57, Finland GISELA GÄSTRIN, MD, radiologist

\section{Suspected chloroquine-resistant malaria in Nigeria}

The emergence of chloroquine-resistant malaria, first reported from South America and South-East Asia, has been suspected in Africa since 1965. Olatunde ${ }^{1}$ described seven cases of resistance suspected on clinical grounds, all from southern Nigeria, while Khan and Maguire, ${ }^{2}$ and Fogh, Jepsen, and Effersøe ${ }^{3}$ studied in detail individual cases originating from Zambia and Kenya respectively. The Kenya case was claimed to be the first confirmed case from that country that met the World Health Organisation's criteria of resistance. Suspicion is growing in northern Nigeria that chloroquine is becoming less certainly effective in treating malaria, and our suspicion is based on cases like the following. 